\title{
Standardising the measurement of physical activity in people receiving haemodialysis: considerations for research and practice
}

Hannah M. L. Young ${ }^{1 *}$ (D), Mark W. Orme ${ }^{1,2}$, Yan Song ${ }^{3,4}$, Maurice Dungey ${ }^{5}$, James O. Burton ${ }^{5,6}$, Alice C. Smith ${ }^{3+}$ and Sally J. Singh ${ }^{1,2,6+}$

\begin{abstract}
Background: Physical activity (PA) is exceptionally low amongst the haemodialysis (HD) population, and physical inactivity is a powerful predictor of mortality, making it a prime focus for intervention. Objective measurement of PA using accelerometers is increasing, but standard reporting guidelines essential to effectively evaluate, compare and synthesise the effects of PA interventions are lacking. This study aims to (i) determine the measurement and processing guidance required to ensure representative PA data amongst a diverse HD population, and; (ii) to assess adherence to PA monitor wear amongst HD patients.

Methods: Clinically stable HD patients from the UK and China wore a SenseWear Armband accelerometer for 7 days. Step count between days (HD, Weekday, Weekend) were compared using repeated measures ANCOVA. Intraclass correlation coefficients (ICCS) determined reliability ( $\geq 0.80$ acceptable). Spearman-Brown prophecy formula, in conjunction with a priori $\geq 80 \%$ sample size retention, identified the minimum number of days required for representative PA data.

Results: Seventy-seven patients (64\% men, mean \pm SD age $56 \pm 14$ years, median (interquartile range) time on HD 40 (19-72) months, 40\% Chinese, 60\% British) participated. Participants took fewer steps on HD days compared with non-HD weekdays and weekend days (3402 [95\% Cl 2665-4140], 4914 [95\% Cl 3940-5887], 4633 [95\% Cl 3558-5707] steps/day, respectively, $p<0.001$ ). PA on HD days were less variable than non-HD days, (ICC 0.723-0.839 versus $0.559-0.611$ ) with $\geq 1 \mathrm{HD}$ day and $\geq 3$ non-HD days required to provide representative data. Using these criteria, the most stringent wear-time retaining $\geq 80 \%$ of the sample was $\geq 7 \mathrm{~h}$.

Conclusions: At group level, a wear-time of $\geq 7 \mathrm{~h}$ on $\geq 1 \mathrm{HD}$ day and $\geq 3$ non-HD days is required to provide reliable PA data whilst retaining an acceptable sample size. PA is low across both HD and non- HD days and future research should focus on interventions designed to increase physical activity in both the intra and interdialytic period.
\end{abstract}

Keywords: Accelerometry, End-stage renal disease, Exercise, Haemodialysis, Physical activity

\footnotetext{
* Correspondence: Hannah.young@uhl-tr.nhs.uk

†Sally J Singh joint senior authors

${ }^{1}$ Department of Respiratory Science, University of Leicester, Leicester Kidney

Lifestyle Team, Academic Unit, Leicester General Hospital, Gwendolen Road,

Leicester LE4 5PW, UK

Full list of author information is available at the end of the article
}

(c) The Author(s). 2019 Open Access This article is distributed under the terms of the Creative Commons Attribution 4.0 International License (http://creativecommons.org/licenses/by/4.0/), which permits unrestricted use, distribution, and reproduction in any medium, provided you give appropriate credit to the original author(s) and the source, provide a link to the Creative Commons license, and indicate if changes were made. The Creative Commons Public Domain Dedication waiver (http://creativecommons.org/publicdomain/zero/1.0/) applies to the data made available in this article, unless otherwise stated. 


\section{Background}

Physical activity (PA), defined as "any bodily movement produced by skeletal muscle which results in caloric expenditure" [1], is exceptionally low amongst the haemodialysis (HD) population and exacerbated by enforced inactivity during $\mathrm{HD}$ treatment [2, 3]. Cardiovascular disease is the leading cause of death in people receiving HD, which may be compounded by a physically inactive lifestyle [2, 4]. Indeed, physical inactivity is a powerful predictor of mortality in people receiving $\operatorname{HD}[4,5]$ and is further associated with other outcomes, including reduced quality of life $[6,7]$, increased risk of hospitalisation [4, 5] and reduced muscle mass [8], making it a prime focus for intervention. Recent guidance recommends all people living with chronic kidney disease, including those receiving $\mathrm{HD}$, be encouraged to participate in regular PA and exercise [9-11].

Given its importance, a valid [12], unobtrusive and feasible method of measuring PA [13] is required. Consequently, accelerometers are gaining popularity for the quantification of human movement. Several studies have objectively measured PA in the HD population, identifying that PA is significantly lower in this group than in matched sedentary controls [3, 14-19], and is lowest on HD days [3, 16, 18-21]. However, there is currently no guidance on the reporting and processing of data, which is inclusive of a geographically and ethnically diverse HD population. Minimum wear time and number of valid days criteria have been recommended in other chronic diseases [22, 23], but these may not be appropriate for use in the HD population, where PA is restricted by HD treatment. PA behaviour is inherently variable and therefore understanding the number of days and hours of measurement required to obtain representative data is critical to enhancing data quality. This will establish a better understanding of factors associated with PA to help target and tailor interventions, and promote the effective evaluation, comparison and synthesis of PA interventions. Valid wear times are universally inconsistent and scarcely reported in the HD literature, ranging from 8 to 24 hours $[3,16,19,24]$. The minimum number of valid days also varies considerably; between 0 and $3 \mathrm{HD}$ days and 1-4 non-HD days [3, 16, 19, 21, 25, 26]. Adherence with wearing the monitor, which inherently impacts the amount of PA data it is possible to collect, is also rarely reported within HD studies. The collection of PA data in HD patients is challenging due to low adherence [27], but the impact of poor concordance with the monitor, and how to address this in the measurement and analyses of PA data, is unknown and requires further investigation.

Additionally, most studies that have used objective PA measurement have focused primarily upon middle-tohigh income Western countries [3, 14-19, 21, 24], despite a growing prevalence of end-stage renal disease, an exponential increase in the demand for $\operatorname{HD}[28,29]$ and high levels of self-reported physical inactivity within East Asia [26]. It is widely recognised in global surveillance PA data from healthy populations that demographic, geographical and cultural variation in PA levels exists. To date, a single observational study from Japan found no difference between PA levels on HD days and non-HD days, which differs from patterns of PA in Western HD populations [8], highlighting the need for $\mathrm{PA}$ measurement guidance in the $\mathrm{HD}$ population that reflects this diversity [30].

The aims of this study were to (i) determine the measurement and processing guidance to ensure representative PA data amongst a diverse population of people receiving $\mathrm{HD}$, accounting for the potential differences between HD days, weekdays and weekend days and; (ii) to assess adherence to PA monitor wear amongst HD patients.

\section{Methods}

\section{Research design}

Data were collected between 2013 and 2016 and formed a convenience sample comprised of data from participants enrolled in a cross-sectional observational study of PA in a multi-ethnic UK and Chinese population receiving HD (International Standard Randomised Controlled Trial Number:11615440), and baseline data from a previously reported trial of intradialytic exercise [31]. Therefore, no formal sample size calculation was performed for this study. Both studies were approved by the NHS Research Ethics Committee (South East Scotland; 14/EM/1049 and Northampton; 11/EM/0149) and the Ethical Committee of the Affiliated Hospital of Nantong University (Ref 2015-12). All participants provided written informed consent.

\section{Participants and settings}

Participants were recruited from HD units in Leicester, UK and Nantong, China. All participants were prevalent patients aged over 18 years of age. HD was performed thrice weekly for four hours in all participants. Participants were excluded if: they were unable to provide informed consent or, to wear the accelerometer; if they presented with established contraindications to exercise [32]; clinically overt infection within the last six weeks; or had lower limb vascular access.

\section{Recruitment}

Eligible participants were identified by their supervising Nephrologist. The study team provided eligible participants with the study information sheet and, at least $48 \mathrm{~h}$ later, invited them to take part. 


\section{Physical activity}

PA was measured using the SenseWear Armband (SWA) Pro 3 (BodyMedia, Inc., Pittsburgh PA, USA). The SWA is a validated multisensor monitor which combines information from a biaxial accelerometer with other sensors measuring heat flux, temperature and galvanic skin response, and widely used in HD groups [12, 33]. Participants were instructed to wear the armband as per manufacturer instructions on their vascular accessfree arm. They were instructed to wear the monitor for 7 consecutive days, which included their usual HD treatment sessions. Participants were asked to continue to follow their usual care schedules, removing the armband for bathing only.

Data from the SWA were processed in 60-s epochs. Non-wear was identified automatically by the SWA from a loss of physiological parameters. Step count and waking wear time (defined as total wear time minus sleep according to SWA proprietary algorithm) were extracted for each day the device was worn for at least one hour.

Average step counts were created for all days for each participant across a range of minimum wear time criteria; $\geq 1 \mathrm{~h}$ to $\geq 12 \mathrm{~h}$ in one-hour increments. Variability in PA across different days was examined by classifying days as either HD days (days on which participants received HD treatment), weekdays (Monday to Fridays when HD treatment not received), and weekends (Sunday for all patients and additionally Saturday for those who received HD treatment in the Monday, Wednesday, Friday cohort). Differences PA between these types of days, the variability in wear time and step count was examined using hourly summaries. Where HD session times were recorded, adherence to the monitor during HD sessions was assessed.

\section{Other measures}

Patient demographic and clinical data were extracted from participants' medical records. Co-morbidity was assessed using the Charlson Comorbidity Index (CCI) modified for use in people receiving HD [34].

\section{Data processing and analysis}

Sample characteristics are presented as mean \pm standard deviation, median (IQR) or $\mathrm{n}(\%)$, as appropriate. The first step of determining measurement guidance was to determine differences between types of day across a range of minimum wear time criteria for step count and wear time, and differences in wear-time and step count between wear time criteria for each type of day, in order to understand how PA data should be organised for analysis. These analyses were conducted using repeatedmeasures analysis of covariance (ANCOVA; waking wear time). Greenhouse-Geisser adjusted F was used to determine statistical significance and post-hoc Bonferroni pairwise comparisons used to identify pairwise differences.

Following this, intraclass correlation coefficients (ICC; two-way mixed; consistency) were calculated across a range of wear time criteria for each type of day. The minimum number of days required to obtain representative PA data (represented by an ICC $\geq 0.80$ ) [35] was estimated using the Spearman-Brown prophecy formula [36, 37]. The influence of increasing wear time and number of valid days on sample size retention was also examined, with an acceptable sample size retention set at $80 \%$. All statistical analyses were performed using SPSS 24 (IBM UK Ltd., UK) with alpha set at 0.05 .

\section{Results}

\section{Recruitment and participant flow}

PA data was available for 77 participants (Fig. 1). Participants wore the activity monitor each day for an average $13.8 \pm 0.38$ waking hours and took an average of $4010 \pm$ 3145 steps/day.

\section{Participant characteristics}

Participants demographic characteristics are outlined in Table 1 . The majority $(N=49,64 \%)$ of participants were male and the mean age was $56 \pm 14$. UK-based participants were from ethnically diverse backgrounds,

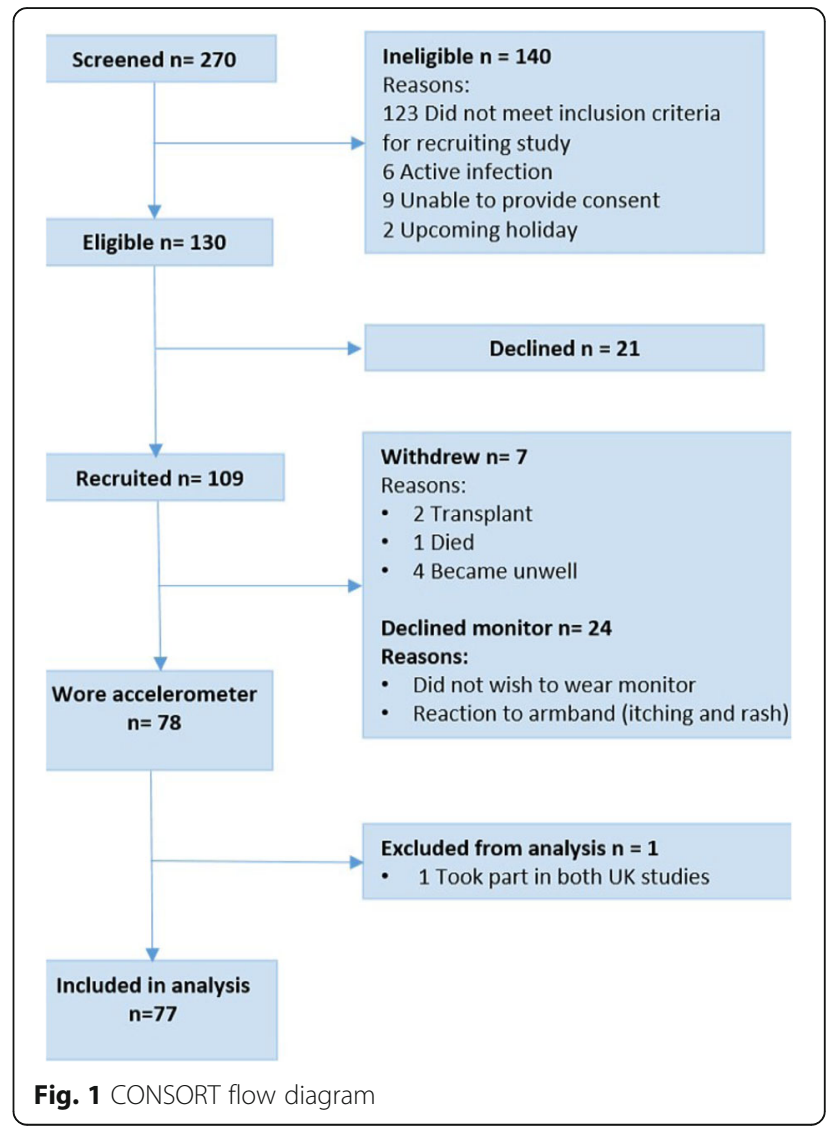


Table 1 Participant characteristics

\begin{tabular}{|c|c|}
\hline & Total $(n=77)$ \\
\hline$\overline{\text { Age }(\text { years) }}{ }^{a}$ & $56 \pm 14$ \\
\hline \multicolumn{2}{|l|}{ Sex n (\%) } \\
\hline Female & $28(36)$ \\
\hline Male & $49(64)$ \\
\hline \multicolumn{2}{|l|}{ Country n (\%) } \\
\hline \multicolumn{2}{|l|}{ British } \\
\hline White British & $26(34)$ \\
\hline Indian & $17(22)$ \\
\hline Any other Asian background & $1(1)$ \\
\hline Caribbean & $1(1)$ \\
\hline Any other black background & $1(1)$ \\
\hline Chinese & $31(40)$ \\
\hline \multicolumn{2}{|l|}{ Diagnosis n (\%) } \\
\hline Glomerulonephritis & $31(40)$ \\
\hline Diabetic Nephropathy & $11(14)$ \\
\hline Renal vascular disease & $9(12)$ \\
\hline Aetiology unknown & $8(10)$ \\
\hline Polycystic Kidney Disease & $7(9)$ \\
\hline Chronic Pyelonephritis & $5(7)$ \\
\hline Membranous nephropathy & $2(3)$ \\
\hline Light chain deposition disease & $1(1)$ \\
\hline Systemic Lupus Erythematosus & $1(1)$ \\
\hline Cyclosporine A Nephropathy & $1(1)$ \\
\hline Other genetic kidney disease & $1(1)$ \\
\hline Time on HD (months) & $40(19-72)$ \\
\hline BMI $\left(\mathrm{kg} / \mathrm{m}^{2}\right)$ & $24.00(21.30-28.40)$ \\
\hline Charlson comorbidity index & $3(2-5)$ \\
\hline \multicolumn{2}{|l|}{ Previous transplant n (\%) } \\
\hline No & $68(88)$ \\
\hline Yes & $9(12)$ \\
\hline Haemoglobin ${ }^{a}(\mathrm{~g} / \mathrm{dl})$ & $11.57 \pm 1.48$ \\
\hline Albumin ${ }^{a}(g / l)$ & $39.19 \pm 4.49$ \\
\hline CRP (mg/L) & $5.00(3.75-7.00)$ \\
\hline \multicolumn{2}{|l|}{ Use of ESA n (\%) } \\
\hline Yes & $69(90)$ \\
\hline No & $8(10)$ \\
\hline
\end{tabular}

Data reported as median (interquartile range) unless stated. ${ }^{a}$ mean and SD. Abbreviations: BMI Body mass index, CRP C-Reactive Protein, ESA Erythropoietin stimulating agent, $H D$ haemodialysis comprising participants who were primarily of White British ( $N=26,56 \%$ of the UK sample) and Indian descent ( $N=17,37 \%$ of the UK sample). The most frequent primary causes of Chronic Kidney Disease were Glomerulonephritis $(N=31,40 \%)$ and Diabetic Nephropathy $(N=11,14 \%)$. Participants had been receiving HD for a median of 40 months (19-72). They had a low burden of co-morbid disease (CCI score 3, interquartile range 2$5)$, the most commonly reported co-morbidities were hypertension $(N=53,32 \%)$, diabetes $(N=16,10 \%)$ and ischaemic heart disease $(N=13,8 \%)$.

\section{Comparison of wear time between haemodialysis days, weekdays and weekends}

Across all wear time criteria, participants wore the monitor for significantly fewer minutes on HD days (803 [95\% CI 759-847] minutes/day) than weekdays (951 [95\% CI 913-989] minutes/day, $p<0.001$ ) and weekends (972 [95\% CI 934-1009] minutes/day $p<$ 0.001) (Additional file 1: Table S1). During the fourhour HD sessions for ( $N=60,78 \%$ of the sample), the SWA was not worn for $1.5 \pm 1.3 \mathrm{~h} / \mathrm{HD}$ session (37\% of an HD session).

\section{Comparison of step count between haemodialysis days weekdays and weekends}

Step count on HD days (3402 [95\%CI 2665-4140] steps/ day) was significantly lower than on weekdays across all wear time criteria (4914 [95\%CI 3940-5887] steps/day,

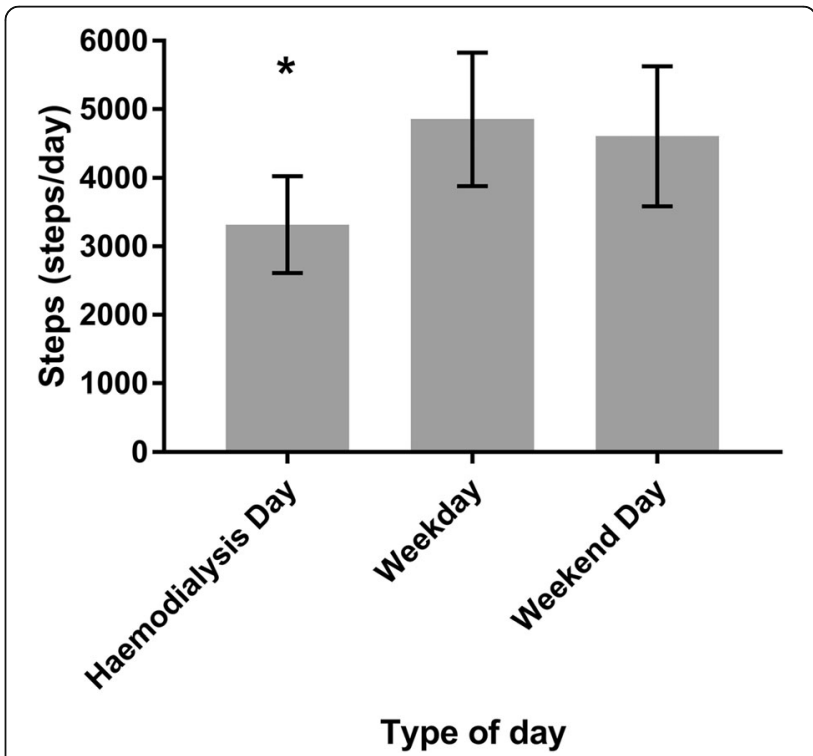

Fig. 2 Adjusted average daily step count. Data presented as mean $(95 \% \mathrm{Cl})$ for haemodialysis days (days on which participants received haemodialysis treatment), weekdays (Monday to Fridays when HD treatment not received) and weekend days (Sunday for all patients and additionally Saturday for those who received HD treatment in the Monday, Wednesday, Friday cohort) 
$p<0.001)$ and weekend days (4633 [95\%CI 3558-5707] steps/day, $p<0.001$ ) (Fig. 2, Additional file 2: Table S2). Findings were unchanged after controlling for waking wear time (Additional file 3: Table S3). Weekday and weekend wear time and step count data were subsequently pooled to form non-HD days, used from this point forward.

\section{Variance in step count between types of day}

Based on all three HD days, all ICCs from a wear time criteria $\geq 7 \mathrm{~h}$ were $>0.80$ ( $\geq 7 \mathrm{~h}$ ICC 0.815 ), Table 2$)$, indicating that one HD day was sufficient to provide representative PA data (Table 2). For all four non-HD days,

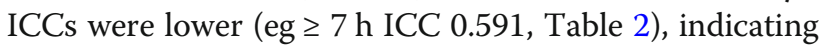
that a single day of data is insufficient. Using the Spearman-Brown formula, at least 3 non-HD days (out of a possible four) were required to obtain representative PA data.

Using criteria of at least one HD day and 3 non-HD days, the most stringent wear time criteria retaining at least $80 \%$ of the sample was $\geq 7 \mathrm{~h}$ ( $82 \%$ sample retention, Fig. 3, Additional file 4: Table S4). Therefore, at the group level, $\geq 1$ HD day and $\geq 3$ non-HD days each with $\geq 7 \mathrm{~h}$ of waking wear time are recommended to obtain PA date representative of a week involving HD treatment.

\section{Discussion}

This study is the first to provide recommendations for the measurement and processing of objective PA data in a diverse population of people receiving HD. We observed significantly reduced adherence with device wear on an HD days, partly driven by poor compliance during the HD session. Patients were less physically active on HD days compared with non-HD days. We recommend that $\geq 7 \mathrm{~h}$ of waking wear time on $\geq 1 \mathrm{HD}$ day and $\geq$

3non-HD days is required to provide reliable PA data, whilst retaining an acceptable sample size.

The current study suggests that due to reduced variability in PA on HD days, at least $7 \mathrm{~h}$ of data are required on at least one HD day, and three non-HD days are required to obtain representative PA data. There is no published consensus on how many days and hours of data are required to capture representative data in an HD population, but our findings align with work in other populations living with long-term conditions. A single day of at least $11 \mathrm{~h}$ data was representative of PA in a cohort of inpatients living with Chronic Obstructive Pulmonary Disease, as activity restriction enforced by hospitalisation (comparable to an HD day) reduced variability in step count [38]. In the same population, in free-living conditions (akin to non-HD days in the current study), 4 days of at least $8 \mathrm{~h}$ of wear time have been recommended [22]. In healthy populations, a period of 2-6 days, inclusive of weekend days is required for the accurate analyses of a range of PA outcomes [39]. The specific patterns of activity between HD and non-HD days in the current study underline the need for specific measurement guidance in this population to accurately capture representative and reliable PA data.

Recommendations for capturing PA data within an HD population are summarised within Table 3 . Wear time and valid day recommendations are not protocol recommendations, and study participants should wear the activity monitor for 7 days in the anticipation that not all participants will achieve this level of adherence, but may manage to wear the monitor for the minimum number of days and hours required for reliable analyses. The recommendations are of value for those who are less adherent because they outline the minimum level at which clinicians and researchers can have confidence that the data are sufficiently reliable. This is particularly relevant considering that adherence to wearing devices can be particularly low within the HD population [40]. Retaining the greatest amount of data for analysis without compromising the quality of the data and the sample size has important implications for the statistical power of a trial and the representativeness of the cohort included [22, 23].

In the current study, wear-time during the HD session was low, with the device removed for $37 \%$ of the time. This may be due to the wear location of the device used. The SWA is worn on the posterior aspect of the arm, proximal to the elbow, on the non-fistula side. Consequently, participants may have been required to remove it to allow for blood pressure measurement to be taken during HD; and subsequently left it off. Other devices, such as those worn on the wrist, may not be subject to these issues. The number of wear locations and types of devices, available for monitoring physical behaviours still plagues the standardisation of physical activity measurement.

People receiving HD were inactive on all days of the week and would be classified as having a 'sedentary lifestyle' based on the threshold of $<5000$ steps per day, regardless of the day of the week [41]. This finding is supported by previous research [3, 24]. Given the link between high levels of inactivity and poor outcomes, providing support and opportunities for people receiving HD to become more active should be an essential component of routine care. Intradialytic exercise (IDE), typically delivered during $\mathrm{HD}$, is the predominant form of rehabilitation for patients [42], but the low levels of PA on non-dialysis days observed in the present study, indicate that a greater focus on increasing PA in the interdialytic period is also warranted $[40,43]$. People receiving HD are less restricted within the interdialytic period and may be more able to engage in interventions covering a wider range of activities, within the context of their usual daily routine 


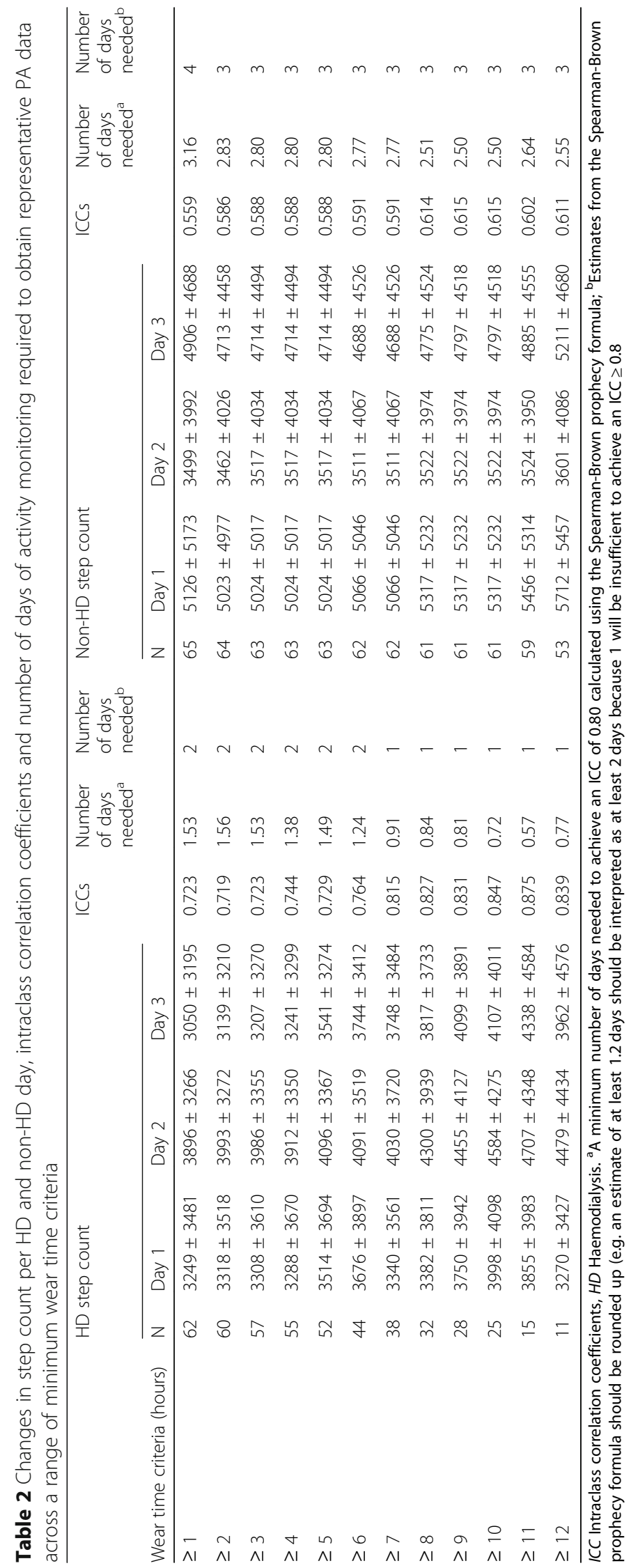




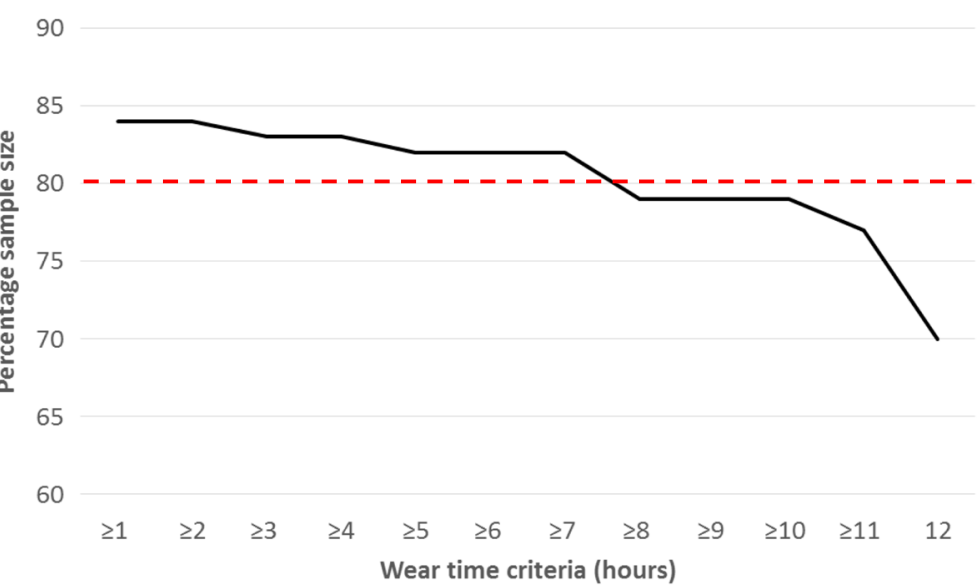

Fig. 3 Sample attrition across a range of wear time criteria $(\geq 1-12 h)$ when recommendations of 1 day HD and 3 days non-HD data are applied. Data are expressed as $n$ and $\%$ of participants. The threshold for $80 \%$ sample attrition represented by the dashed line

[44]. Currently, there is limited evidence that IDE directly influences habitual PA [45, 46] and relatively few trials evaluating the effects of interdialytic PA interventions for people receiving HD [46, 47]. Future trials should seek to address this gap in the literature. The use of the standardised measurement guidance for PA behaviours in HD presented here should allow for a more robust comparison of PA interventions, the impact of different regimes of dialysis (for example those undertaking twice-weekly HD, shorter sessions of HD and nocturnal HD) on PA, and will facilitate the identification of groups who may be particularly inactive.

This study is the first to report recommendations for the measurement and processing of objective PA data in the context of $\mathrm{HD}$, and a main strength of our approach is the inclusion of a geographically and demographically diverse population of people receiving $\mathrm{HD}$, creating robust guidance that is widely applicable. The use of step count as a marker for PA allows findings to be readily understandable and clinically meaningful. However, step count does not represent the intensity of $\mathrm{PA}$, and it is unclear whether our recommendations are optimal for other PA metrics [22]. Additionally, the SWA has been shown to

Table 3 Summary of recommendations for the objective measurement of representative physical activity data in people receiving $\mathrm{HD}$

Individuals should wear the monitor for a 7-day protocol

Include data in the analysis if data satisfies the following conditions:

$\cdot \geq 3$ non-HD days

$\cdot \geq 1 \mathrm{HD}$ day

$\cdot \geq 7 \mathrm{~h}$ of data on either type of day

$H D$ haemodialysis underestimate step count in other chronic disease populations with low walking speeds [48].

\section{Conclusion}

PA in people receiving $\mathrm{HD}$ is low on all days, but particularly on days undergoing HD. When analysing objectively measured PA at group level, a wear-time of $\geq 7 \mathrm{~h}$ on both $\geq 1$ HD day and $\geq 3$ non-HD days is required to provide reliable data. Participants should also be encouraged to wear the monitor for as long as possible during the HD session. These recommendations will promote the standardised assessment of PA, enhancing data quality and thus ensuring that PA interventions can be effectively evaluated, compared and synthesised.

\section{Supplementary information}

Supplementary information accompanies this paper at https://doi.org/10. 1186/s12882-019-1634-1.

Additional file 1: Table S1. Unadjusted average daily wear time in minutes across a range of minimum wear time criteria.

Additional file 2: Table S2. Unadjusted average daily step count across a range of minimum wear time criteria. Data for all days, haemodialysis days (HD), weekdays (WD) and weekends (WE)

Additional file 3: Table S3. Average daily step count across a range of minimum wear time criteria, adjusted for wear time.

Additional file 4: Table S4. Sample attrition across a range of wear time criteria ( $\geq 1-12 \mathrm{~h}$ ) when recommendations of 1 day HD and 3 days non-HD data are applied.

\section{Abbreviations}

ANCOVA: Analysis of covariance; BMI: Body mass index; CRP: C-reactive protein; ESA: Erythropoietin stimulating agent; HD: Haemodialysis; ICC: Intraclass correlation coefficient; IDE: Intradialytic exercise; NHS: National Health Service; PA: Physical activity; SWA: Sense Wear Armband

\section{Acknowledgements}

The authors would like to thank the staff and patients at all units, Fresenius Medical Care and The Leicester Kidney Care Appeal. 


\section{Authors contributions}

Research idea and study design: SJS, ACS, MWO HMLY; data acquisition: YS, MD, HMLY; data analysis and interpretation: HMLY, MWO; statistical analysis: HMLY, MWO; supervision and mentorship: SJS, ACS, JOB MWO; manuscript preparation: HMLY, MWO. Each author contributed important intellectual content during manuscript drafting or revision and accepts accountability for the overall work by ensuring that questions pertaining to the accuracy or integrity of any portion of the work are appropriately investigated and resolved. All authors have read and approved the final version.

\section{Funding}

The research was supported by the National Institute for Health Research (NIHR) Leicester Biomedical Research Centre, Collaboration for Leadership in Applied Health Research and Care East Midlands (CLAHRC EM) and partly funded by the Stoneygate Trust. H.M.L.Y. and J.O.B. are supported by grants from the NIHR (DRF-2016-09-015 and CS-2013-13-014). S.J.S. is supported by the Collaboration for Leadership in Applied Health Research and Care East Midlands. The views expressed in this publication are those of the authors and not necessarily those of the NHS, the National Institute for Health Research or the Department of Health. The funders had no role in the study design; collection, analysis, and interpretation of the data; writing the report; and the decision to submit the report for publication.

\section{Availability of data and materials}

The datasets used and analysed during the current study are available from the corresponding author on reasonable request.

\section{Ethics approval and consent to participate}

Studies used for this analyses were approved by the NHS Research Ethics Committee (South East Scotland; 14/EM/1049 and Northampton; 11/EM/ 0149) and the Ethical Committee of the Affiliated Hospital of Nantong University (Ref 2015-12). All participants provided written informed consent.

\section{Consent for publication}

The results presented in this paper have not been published previously in whole or part, except in abstract form at the ERA-EDTA 2019 conference in Budapest. Permission for publication has been obtained from the copyright holder.

\section{Competing interests}

The authors declare that they have no competing interests.

\section{Author details}

'Department of Respiratory Science, University of Leicester, Leicester Kidney Lifestyle Team, Academic Unit, Leicester General Hospital, Gwendolen Road, Leicester LE4 5PW, UK. ${ }^{2}$ Centre for Exercise and Rehabilitation Science, NIHR Leicester Biomedical Research Centre - Respiratory, Glenfield Hospital, University Hospitals of Leicester NHS Trust, Leicester, UK. ${ }^{3}$ Department of Health Sciences, University of Leicester, Leicester, UK. ${ }^{4}$ Nantong University, Nantong, China. ${ }^{5}$ Department of Cardiovascular Science, University of Leicester, Leicester, UK. ${ }^{6}$ National Centre for Sport and Exercise Medicine, Loughborough University, Loughborough, UK.

\section{Received: 15 July 2019 Accepted: 20 November 2019}

\section{Published online: 04 December 2019}

\section{References}

1. Caspersen CJ, Powell KE, Christenson GM. Physical activity, exercise, and physical fitness: definitions and distinctions for health-related research. Public Health Rep. 1985;100:126.

2. National Institutes of Health, National Institute of Diabetes and Digestive and Kidney Diseases. United states renal data system. 2018 USRDS annual data report: Epidemiology of kidney disease in the united states. , bethesda, MD, 2018. https://www.usrds.org/2018/view/Default.aspx. Updated 2018.

3. Avesani CM, Trolonge S, Deleaval $P$, et al. Physical activity and energy expenditure in haemodialysis patients: an international survey. Nephrol Dial Transplant. 2012;27(6):2430-4

4. Stack AG, Molony DA, Rives T, Tyson J, Murthy BV. Association of physical activity with mortality in the US dialysis population. Am J Kidney Dis. 2005; 45(4):690-701.
5. O'Hare AM, Tawney K, Bacchetti P, Johansen KL. Decreased survival among sedentary patients undergoing dialysis: results from the dialysis morbidity and mortality study wave 2. Am J Kidney Dis. 2003;41(2):447-54.

6. Lopes AA, Lantz B, Morgenstern $H$, et al. Associations of self-reported physical activity types and levels with quality of life, depression symptoms, and mortality in hemodialysis patients: the DOPPS. Clin J Am Soc Nephrol. 2014;9(10):1702-12.

7. Tentori F, Elder SJ, Thumma J, et al. Physical exercise among participants in the dialysis outcomes and practice patterns study (DOPPS): correlates and associated outcomes. Nephrol Dial Transplant. 2010;25(9):3050-62.

8. Morishita Y, Kubo K, Miki A, Ishibashi K, Kusano E, Nagata D. Positive association of vigorous and moderate physical activity volumes with skeletal muscle mass but not bone density or metabolism markers in hemodialysis patients. Int Urol Nephrol. 2014;46(3):633-9.

9. National Institute of Health and Care Excellence, (NICE). Chronic kidney disease in adults: Assessment and management. https://www.nice.org.uk/ guidance/cg182? unlid=359129534201673065437. Updated 2014. Accessed August 25th, 2016.

10. Guideline Development Group, Bilo H, Coentrão L, et al. Clinical practice guideline on management of patients with diabetes and chronic kidney disease stage $3 \mathrm{~b}$ or higher (eGFR $<45 \mathrm{~mL} / \mathrm{min}$ ). Nephrol Dial Transplant. 2015;30(suppl_2):ii142.

11. KDIGO. KDIGO clinical practice guideline for the management of blood pressure in chronic kidney disease. http://www.kdigo.org/clinical_practice_ guidelines/pdf/KDIGO_BP_GL.pdf. Updated 2012. Accessed July, 2017.

12. Johannsen DL, Calabro MA, Stewart J, Franke W, Rood JC, Welk GJ. Accuracy of armband monitors for measuring daily energy expenditure in healthy adults. Med Sci Sports Exerc. 2010;42(11):2134-40.

13. Painter $P$, Marcus RL. Assessing physical function and physical activity in patients with CKD. Clin J Am Soc Nephrol. 2013;8(5):861-72.

14. Broers NJ, Martens RJ, Cornelis T, et al. Physical activity in end-stage renal disease patients: the effects of starting dialysis in the first 6 months after the transition period. Nephron. 2017;137(1):47-56.

15. Cupisti A, Capitanini A, Betti G, D'alessandro C, Barsotti G. Assessment of habitual physical activity and energy expenditure in dialysis patients and relationships to nutritional parameters. Clin Nephrol. 2011;75(3):218

16. Gomes EP, Reboredo MM, Carvalho EV, et al. Physical activity in hemodialysis patients measured by triaxial accelerometer. Biomed Res Int. 2015;2015:645645

17. Johansen $\mathrm{KL}$, Chertow GM, Ng AV, et al. Physical activity levels in patients on hemodialysis and healthy sedentary controls. Kidney Int. 2000;57(6): 2564-70.

18. Kopple JD, Kim JC, Shapiro BB, et al. Factors affecting daily physical activity and physical performance in maintenance dialysis patients. J Ren Nutr. 2015;25(2):217-22.

19. Baria F, Kamimura MA, Avesani CM, et al. Activity-related energy expenditure of patients undergoing hemodialysis. J Ren Nutr. 2011; 21(3):226-34

20. Williams S, Han M, Ye X, et al. Physical activity and sleep patterns in hemodialysis patients in a suburban environment. Blood Purif. 2017;43(1-3): 235-43.

21. Kim JC, Shapiro BB, Zhang M, et al. Daily physical activity and physical function in adult maintenance hemodialysis patients. J Cachexia Sarcopenia Muscle. 2014;5(3):209-20.

22. Demeyer $\mathrm{H}$, Burtin C, Van Remoortel $\mathrm{H}$, et al. Standardizing the analysis of physical activity in patients with COPD following a pulmonary rehabilitation program. Chest. 2014;146(2):318-27.

23. Matthews CE, Hagströmer M, Pober DM, Bowles HR. Best practices for using physical activity monitors in population-based research. Med Sci Sports Exerc. 2012;44(1 Suppl 1):S68.

24. da Costa Rosa CS, Nishimoto DY, Júnior IFF, Ciolac EG, Monteiro HL. Factors associated with levels of physical activity in chronic kidney disease patients undergoing hemodialysis: the role of dialysis versus nondialysis day. J Phys Act Health. 2017;14(9):726-32.

25. Majchrzak KM, Pupim LB, Chen K, et al. Physical activity patterns in chronic hemodialysis patients: comparison of dialysis and nondialysis days. J Ren Nutr. 2005;15(2):217-24.

26. Matsuzawa R, Matsunaga A, Wang G, et al. Habitual physical activity measured by accelerometer and survival in maintenance hemodialysis patients. Clin J Am Soc Nephrol. 2012;7(12):2010-6. 
27. Mafra D, Fouque D. Lower physical activity and depression are associated with hospitalization and shorter survival in CKD. Clin J Am Soc Nephrol. 2014;9(10):1669-70.

28. Zhou L, Zeng X, Fu P. Community hemodialysis in China: opportunities and challenges. Chin Med J. 2017;130(18):2143.

29. Prasad N, Jha V. Hemodialysis in asia. Kidney Dis. 2015;1(3):165-77.

30. Hallal PC, Andersen LB, Bull FC, et al. Global physical activity levels: surveillance progress, pitfalls, and prospects. Lancet. 2012;380(9838):247-57.

31. Dungey M, Young HML, Churchward DR, Burton JO, Smith AC, Bishop NC. Regular exercise during haemodialysis promotes an anti-inflammatory leucocyte profile. Clin Kidney J. 2017;10(6):813-21.

32. American College of Sports Medicine. ACSM's guidelines for exercise testing and prescription Philadelphia: Lippincott Williams \& Wilkins; 2013.

33. St-Onge M, Mignault D, Allison DB, Rabasa-Lhoret R. Evaluation of a portable device to measure daily energy expenditure in free-living adults. Am J Clin Nutr. 2007:85(3):742-9.

34. Beddhu S, Bruns FJ, Saul M, Seddon P, Zeidel ML. A simple comorbidity scale predicts clinical outcomes and costs in dialysis patients. Am J Med. 2000;108(8):609-13.

35. Baranowski T, Mâsse LC, Ragan B, Welk G. How many days was that? We're still not sure, but we're asking the question better! Med Sci Sports Exerc. 2008:40(7 Suppl):S544.

36. Spearman C. "General intelligence," objectively determined and measured. Am J Psychol. 1904;15(2):201-92.

37. Spearman C. The proof and measurement of association between two things. Am J Psychol. 1904;15(1):72-101.

38. Orme MW, Harvey-Dunstan TC, Boral I, et al. Changes in physical activity during hospital admission for chronic respiratory disease. Respirology. 2019;24(7):652-7.

39. Dillon CB, Fitzgerald AP, Kearney PM, et al. Number of days required to estimate habitual activity using wrist-worn GENEActiv accelerometer: a cross-sectional study. PLoS One. 2016;11(5):e0109913.

40. Mendoza M, Han M, Meyring-Wosten A, Wilund K, Kotanko P. It's a nondialysis day... do you know how your patient is doing? A case for research into interdialytic activity. Blood Purif. 2015;39(1-3):74-83.

41. Tudor-Locke C, Craig CL, Thyfault JP, Spence JC. A step-defined sedentary lifestyle index:< 5000 steps/day. Appl Physiol Nutr Metab. 2012:38(2):100-14.

42. Konstantinidou E, Koukouvou G, Kouidi E, Deligiannis A, Tourkantonis A. Exercise training in patients with end-stage renal disease on hemodialysis: comparison of three rehabilitation programs. J Rehabil Med. 2002;34(1):40-5.

43. Han M, Ye X, Preciado P, et al. Relationships between neighborhood walkability and objectively measured physical activity levels in hemodialysis patients. Blood Purif. 2018;45(1-3):236-44.

44. Shearer NBC. Health empowerment theory as a guide for practice. Geriatr Nurs. 2009;30(2):4-10.

45. Cho J, Lee J, Lee S, Park H, Choi S, Kim JC. Effect of intradialytic exercise on daily physical activity and sleep quality in maintenance hemodialysis patients. Int Urol Nephrol. 2018;50(4):745-54

46. Bohm C, Stewart K, Onyskie-Marcus J, Esliger D, Kriellaars D, Rigatto C. Effects of intradialytic cycling compared with pedometry on physical function in chronic outpatient hemodialysis: a prospective randomized trial. Nephrol Dial Transplant. 2014;29(10):1947-55.

47. Han M, Williams S, Mendoza M, et al. Quantifying physical activity levels and sleep in hemodialysis patients using a commercially available activity tracker. Blood Purif. 2016;41(1-3):194-204.

48. Van Remoortel H, Raste $Y$, Louvaris Z, et al. Validity of six activity monitors in chronic obstructive pulmonary disease: a comparison with indirect calorimetry. PLoS One. 2012;7(6):e39198.

\section{Publisher's Note}

Springer Nature remains neutral with regard to jurisdictional claims in published maps and institutional affiliations.

Ready to submit your research? Choose BMC and benefit from:

- fast, convenient online submission

- thorough peer review by experienced researchers in your field

- rapid publication on acceptance

- support for research data, including large and complex data types

- gold Open Access which fosters wider collaboration and increased citations

- maximum visibility for your research: over $100 \mathrm{M}$ website views per year

At BMC, research is always in progress.

Learn more biomedcentral.com/submissions 